\title{
STUDI KOMPARATIF KEUNTUNGAN BUDIDAYA JAMUR MERANG PADA MEDIA JERAMI DAN MEDIA TANDAN KOSONG KELAPA SAWIT (STUDI KASUS PADA USAHATANI BEUNA RASEUKI) DI GAMPONG PEUJEURAT DESA BATOH BANDA ACEH
}

\author{
(Comparative Study Benefits of Straw Mushroom on Media Planting Straw and Media \\ Planting Oil Plam Bunches (Case Study on Beuna Raseuki's Farm) in Peujeurat Batoh \\ Village Lueng Bata Sub-Districts Banda Aceh)
}

\author{
Syarifah Ulfami, Edy Marsudi, Azhar* \\ ${ }^{1}$ Program Studi Agribisnis, Fakultas Pertanian, Universitas Syiah Kuala
}

\begin{abstract}
Abstrak. Dalam upaya meningkatkan produksi dan memenuhi permintaan pasar, para petani harus mampu mendapatkan media tanam dengan kualitas yang baik dan mampu memanfaatkan media tanam tersebut dengan baik. Pemilihan media tanam sangat berpengaruh pada peningkatan produksi jamur merang. Tujuan penelitian ini yaitu untuk melihat besarnya keuntungan yang didapatkan dari penggunaan media tanam tandan kosong kelapa sawit (TKKS) dibandingkan dengan penggunaan media tanam jerami. Metode penelitian yang digunakan adalah metode studi kasus dengan analisis kualitatif (deskriptif) dan analisis finansial berupa analisis pendapatan dan uji hipotesis $\mathrm{T}$, kuantitatif. Hasil penelitian menunjukkan nilai $\mathrm{R} / \mathrm{C}$ pada budidaya jamur merang dengan menggunakan media tanam jerami pada periode ke empat, ke lima dan ke enam $<1$, maka penggunaan media tanam jerami tidak dianjurkan karena tidak selalu memberikan keuntungan bagi budidaya jamur merang. Penggunaan media tanam tandan kosong kelapa sawit (TKKS) untuk budidaya jamur merang sangat dianjurkan karena nilai R/C pada setiap periodenya $>1$. Adapun hasil uji statistik yang diperoleh yaitu 6,72641 > 2,2281 , maka $t_{\text {cari }}>t_{\text {tabel }}$ pada taraf nyata 0,05 . Hal ini menunjukkan bahwa terdapat perbedaan yang nyata antara pendapatan budidaya jamur merang yang menggunakan media tandan kosong kelapa sawit (TKKS) dengan pendapatan budidaya jamur merang yang menggunakan media jerami. Sehingga penggunaan media tanam tandan kosong kelapa sawit lebih menguntungkan dibandingkan dengan penggunaan media tanam jerami.
\end{abstract}

Kata kunci: Keuntungan, Media Tanam Tandan Kosong Kelapa Sawit, Perbandingan, Media Tanam Jerami

Abstract. In an effort to increase production and meet market demand, the farmers should be able to get the media planting with good quality and able to utilize the planting medium well. Selection of planting medium is very influential on increasing production of mushroom. The purpose of this study is to see the amount of benefits obtained from the use of planting media empty palm bunches (TKKS) compared with the use of straw planting media. The research method used is case study method with qualitative analysis (descriptive) and financial analysis in the form of income analysis and hypothesis $\mathrm{T}$ test, quantitative. The result showed that $\mathrm{R} / \mathrm{C}$ value on mushroom cultivation using straw planting medium on the fourth, fifth and sixth period $<1$, then the use of straw planting media is not recommended because it does not always provide benefits for mushroom cultivation. The use of planting media for empty palm fruit bunches (TKKS) for the cultivation of mushroom is highly recommended because the $\mathrm{R} / \mathrm{C}$ value in each period $>1$. The statistical test results obtained are 6.72641>2.2281, then $\mathrm{t}$ search $>\mathrm{t}$ table at a real level of 0.05. This shows that there is a significant difference between the income of mushroom cultivation using the empty palm oil bunches (TKKS) with the income of mushroom cultivation using straw media. So the use of planting media empty palm oil bunches is more profitable compared with the use of straw planting media.

Keywords: Benefits, Media Planting Oil Palm Bunches, Comparison, Media Planting Straw 


\section{PENDAHULUAN}

Jamur merang dibudidayakan di dalam bangunan yang disebut kumbung. Meskipun disebut jamur merang, tetapi jamur ini tidak hanya dapat tumbuh pada media merang saja. Menurut Sinaga (2008), jamur merang dapat tumbuh pada media yang merupakan limbah pertanian yang merupakan sumber sellulosa, seperti pada jerami, limbah pabrik kertas, tandan kosong kelapa sawit, kompos batang pisang dan kompos bio massa, ampas sagu, dan lain sebagainya. Dengan demikian limbah tidak terbuang sia-sia karena masih dapat member nilai tambah. Bahkan sisa kompos bekas pertanian jamur juga dapat digunakan sebagai pupuk untuk penyubur tanah.

Sejak tahun 1999, jamur merang telah dibudidayakan di Banda Aceh. Usaha jamur merang cocok dikembangkan di Banda Aceh karena iklim dan suhunya yang bagus dan media tanamnya yang mudah didapatkan. Permintaan jamur merang di Banda Aceh semakin meningkat di tingkat agen dan rumah tangga, namun persediaanya yang masih terbatas sehingga belum bisa memenuhi permintaan pasar. Hal ini dikarenakan kurangnya hasil produksi di para petani (Serambi Aceh, 2016). Menurut Adi, pengelola budiaya jamur merang di Gampong Limpok, jamur merang yang diproduksi per hari rata-rata 8-12 kilogram. Sedangkan untuk mencukupi permintaan pasar sekitar 40-50 kilogram per hari. Berkurangnya produksi jamur merang pada saat ini dikarenakan pemanfaatan media tanam sulit didapatkan dengan kualitas yang bagus. Harapan petani jamur merang agar dapat meningkatkan produksi sehingga dapat meningkatkan pendapatan dan mendapatkan keuntungan yang lebih dari usaha budidaya jamur merang akan terwujud dengan menggunakan media tanam yang tepat dalam proses pembudidayaannya.

Dalam pengamatan peneliti selama survei pra penelitian, di Banda Aceh terdapat beberapa usahatani jamur merang. Sebagaian usahatani tersebut membudidayakan jamur merang dengan media tanam tandan kosong kelapa sawit (TKKS) dan sebagian usahatani lainnya membudidayakan dengan menggunakan media tanam jerami. Tetapi terdapat salah satu usahatani yang membudidayakan jamur merang dengan menggunakan kedua media tanam tersebut, yaitu media tanam jerami dan media tanam tandan kosong kelapa sawit (TKKS), usahatani tersebut bernama "Beuna Raseuki". Usahatani ini memiliki empat unit kumbung dengan masing-masing ukuran kumbung yaitu $6 \times 8 \mathrm{~m}^{2}$. Dalam waktu satu periode panen, masing-masing kumbung mampu menghasilkan produksi jamur merang sekitar 120-200 kilogram. Pada waktu-waktu tertentu, produksi jamur merang bisa mencapai diatas 200 kilogram. Hal ini dikarenakan pengaruh kualitas media tanam yang digunakan baik media tanam jerami maupun media tanam tandan kosong kelapa sawit (TKKS).

Tujuan dilaksanakan penelitian ini adalah untuk melihat besarnya keuntungan yang didapatkan dari penggunaan media tanam tandan kosong kelapa sawit (TKKS) dibandingkan dengan penggunaan media tanam jerami.

\section{METODE PENELITIAN}

\section{Lokasi dan Waktu Penelitian}

Penentuan lokasi penelitian ini dilakukan secara sengaja (Purposive) yaitu berlokasi di Gampong Peujeurat Desa Batoh Kecamatan Lueng Bata Banda Aceh. Penentuan lokasi dilakukan dengan secara sengaja karena pertimbangan bahwa lokasi ini menggunakan dua media tanam yaitu media tanam jerami dan media tanam tandan kosong kelapa sawit (TKKS). Penelitian ini dilaksanakan pada bulan November-Januari 2018. 


\section{Objek dan Ruang Lingkup Penelitian}

Objek penelitian ini adalah usahatani budidaya jamur merang "Beuna Raseuki" milik bapak Baharuddin. Ruang lingkup penelitian ini terbatas pada keuntungan yang diperoleh dari produksi jamur merang dengan menggunakan masing-masing media tanam, yaitu media jerami dan media tandan kosong kelapa sawit (TKKS).

\section{Sumber dan Metode Pengumpulan Data}

Metode pengumpulan data dalam penelitian ini menggunakan metode studi kasus. Data yang dikumpulkan didalam penelitian ini terdiri dari data primer dan data sekunder. Data primer merupakan data yang didapatkan melalui pengamatan langsung dan wawancara dengan informan. Sedangkan data sekunder diperoleh melalui studi pustaka dan dari berbagai literatur. Metode analisis data yang digunakan adalah metode kualitatif dan kuantitatif. Metode kualitatif dilakukan dengan analisis deskriptif untuk melihat kegiatan usaha jamur merang di Beuna Raseuki. Analisis deskriptif dilakukan untuk mengetahui karakteristik pelaku usaha jamur merang dan melihat gambaran umum kegiatan usaha jamur merang di Beuna Raseuki, serta melengkapi hasil analisis kuantitatif yang dilakukan. Metode kuantitatif dilakukan dengan analisis finansial untuk mengetahui besar biaya, tingkat pendapatan dan keuntungan yang diperoleh dari usaha jamur merang Beuna Raseuki.

\section{Model Analisis}

\section{Analisis Pendapatan}

Data yang telah dikumpulkan di lapangan, dipindahkan dengan mentabulasikan terlebih dahulu, kemudian data tersebut diolah dalam bentuk tabelaris sesuai dengan kebutuhan analisis pendapatan untuk tingkat keuntungan yang diperoleh dari usaha budidaya jamur merang dengan menggunakan rumus :

\section{a) Perhitungan Total Cost (TC)}

Total cost adalah total biaya yang dikeluarkan oleh produsen dalam menghasilkan output atau produksi (Nicholson, 1999). Secara sistematis, total cost dapat ditulis sebagai berikut :

Dimana :

$$
\mathrm{TC}=\mathrm{FC}+\mathrm{VC}
$$

$$
\begin{array}{ll}
\mathrm{TC} & =\text { Total Cost }(\mathrm{Rp} / \text { Periode Tanam }) \\
\mathrm{FC} & =\text { Fixed Cost }(\mathrm{Rp} / \text { Periode Tanam }) \\
\mathrm{VC} & =\text { Variable Cost }(\mathrm{R} p / \text { Periode Tanam })
\end{array}
$$

\section{b) Perhitungan Total Revenue (TR)}

Total revenue adalah total penerimaan dari perusahaan yang diperoleh dari perkalian antara jumlah barang yang terjual dengan harga barang tersebut (Nicholson, 1999). Secara sistematis, total revenue dapat ditulis sebagai berikut :

Dimana :

$$
\mathrm{TR}=\mathrm{P} \times \mathrm{Q}
$$

$$
\begin{array}{ll}
\mathrm{TR} & =\text { Total Revenue (Rp/Periode Tanam) } \\
\mathrm{P} & =\text { Price }(\mathrm{Rp} / \mathrm{Kg}) \\
\mathrm{Q} & =\text { Quantity }(\mathrm{Kg})
\end{array}
$$




\section{c) Pendapatan $(\pi)$}

Pendapatan adalah selisish antara total penerimaan dan total pengeluaran, dimana pendapatan merupakan pendapatan bersih (Nicholson, 1999). Secara sistematis, pendapatan dapat ditulis sebagai berikut :

Dimana :

$$
\pi \quad=\mathrm{TR}-\mathrm{TC}
$$

TR $=$ Total Revenue $(\mathrm{Rp} /$ Periode Tanam $)$

$\mathrm{TC}=$ Total Cost $((\mathrm{Rp} /$ Periode Tanam $)$

\section{d) Perhitungan Revenue Cost Ratio (R/C)}

Revenue cost ratio (R/C) merupakan perbandingan antara nilai penerimaan (TR) dengan total biaya produksi (TC) (Kadariah dalam Amalia R, 2015). Untuk menghitung RC rasio dengan menggunakan rumus:

Dimana :

$$
\mathrm{R} / \mathrm{C}=\frac{T R}{T C}
$$

$\mathrm{TR}=$ Total Revenue $(\mathrm{Rp} /$ Periode Tanam $)$

TC $\quad=$ Total Cost $((\mathrm{Rp} /$ Periode Tanam $)$

Pada penelitian ini, dilakukan perhitungan biaya penyusutan untuk menggantikan biaya tetap yang digunakan untuk disetiap periode tanam. Menurut Baridwan (2008), metode untuk menghitung biaya penyusutan yaitu mengurangi harga perolehan asset dengan nilai sisa, hal ini menunjukkan total jumlah nilai yang dapat disusutkan, lalu membagi nilai tersebut dengan masa manfaat asset atau taksiran umur kegunaan. Secara sistematis, bentuk persamaan penyusutan dapat ditulis :

$$
\text { Penyusutan }=\frac{(H P-N S)}{n}
$$

Dimana :

$$
\begin{array}{ll}
\mathrm{HP} & =\text { Harga Perolehan (Rp) } \\
\mathrm{NS} & =\text { Nilai Sisa } \\
\mathrm{n} & =\text { Taksiran Umur Kegunaan (Bulan) }
\end{array}
$$

\section{Uji Hipotesis t}

Uji hipotesis t bertujuan untuk mengetahui perbandingan atau perbedaan keuntungan yang terjadi pada media tanam jerami dan media tanam tandan kosong kelapa sawit. Secara sistematis bentuk persamaan uji hipotesis t dapat ditulis (Sudjana, 2002) sebagai berikut :

$$
\mathrm{t}_{\mathrm{cari}}=\frac{\bar{x} 1-\bar{x} 2}{\sqrt{\left(\frac{S 12}{n 1}\right)+\left(\frac{S 22}{n 2}\right)}}
$$

Dimana :

$\bar{x}_{1} \quad=$ Rata-rata pendapatan budidaya jamur merang pada media tanam tandan kosong kelapa sawit (TKKS)

$\bar{x}_{2} \quad=$ Rata-rata pendapatan budidaya jamur merang pada media tanam jerami 
$\mathrm{S}_{1}{ }^{2}=$ Devisiasi standar pendapatan budidaya jamur merang dengan menggunakan media tanam tandan kosong kelapa sawit (TKKS)

$\mathrm{S}_{2}{ }^{2}=$ Devisiasi standar pendapatan budidaya jamur merang dengan menggunakan media tanam jerami

$\mathrm{n}_{1} \quad=$ Banyaknya periode tanam jamur merang dari media tandan kosong kelapa sawit (TKKS)

$\mathrm{n}_{2}=$ Banyaknya periode tanam jamur merang dari media jerami

Uji hipotesis $t$ juga bertujuan untuk membandingkan $t_{\text {cari }}$ dengan $t_{\text {tabel }}$. Apabila hasil perhitungan menunjukkan sebagai berikut :

$\mathrm{F}_{\text {cari }}>\mathrm{F}_{\text {tabel}}$, pada taraf nyata 0,05 maka, $\mathrm{H}_{0}$ ditolak dan $\mathrm{H}_{\mathrm{a}}$ diterima. Hal ini menunjukkan bahwa secara individual, variabel bebas $(\mathrm{X})$ berpengaruh nyata terhadap variabel tidak bebas (Y). $\mathrm{t}_{\text {cari }}<\mathrm{t}_{\text {tabel }}$, pada taraf nyata 0,05 maka, $\mathrm{H}_{0}$ diterima dan $\mathrm{H}_{\mathrm{a}}$ ditolak. Hal ini menunjukkan bahwa secara individual, variabel bebas $(\mathrm{X})$ tidak berpengaruh nyata terhadap variabel tidak bebas $(\mathrm{Y})$.

\section{HASIL PENELITIAN DAN PEMBAHASAN}

\section{Produksi Usahatani Jamur Merang}

Tabel 1. Hasil Produksi Jamur Merang Media Jerami

\begin{tabular}{ccccccccccccccc}
\hline & \multicolumn{10}{c}{ JERAMI } \\
\hline $\begin{array}{c}\text { Periode } \\
\begin{array}{c}\text { Tanam } \\
\text { (Produk } \\
\text { si Ke-) }\end{array}\end{array}$ & $\mathbf{1}$ & $\mathbf{1 0}$ & $\mathbf{3}$ & $\mathbf{4}$ & $\mathbf{5}$ & $\mathbf{6}$ & $\mathbf{7}$ & $\mathbf{8}$ & $\mathbf{9}$ & $\mathbf{1 0}$ & $\mathbf{1 1}$ & $\mathbf{1 2}$ & $\mathbf{1 3}$ & $\mathbf{1 4}$ \\
\hline $\mathbf{1}$ & 5 & 7,8 & 8,2 & 0 & 0 & 18 & 16,2 & 16,8 & 10,3 & 0 & 0 & 20,8 & 12 & 2,4 \\
$\mathbf{2}$ & 7 & 8,1 & 6,9 & 0 & 0 & 19,6 & 15 & 13,5 & 9,7 & 0 & 0 & 22,8 & 15,7 & 3,6 \\
$\mathbf{3}$ & 3 & 5,7 & 7,4 & 0 & 0 & 17 & 18 & 13 & 9,5 & 0 & 0 & 19,6 & 10 & 4,2 \\
$\mathbf{4}$ & 3 & 6 & 8,7 & 0 & 0 & 17,6 & 14 & 10,7 & 8 & 0 & 0 & 12,1 & 6 & 1,3 \\
$\mathbf{5}$ & 4,3 & 7,2 & 9 & 0 & 0 & 18 & 17,6 & 12,1 & 6,5 & 0 & 0 & 11,7 & 7 & 1,6 \\
$\mathbf{6}$ & 5 & 8,4 & 8,9 & 0 & 0 & 16 & 14 & 10,1 & 6 & 0 & 0 & 14 & 5,2 & 1,1 \\
\hline
\end{tabular}

Sumber: Data Primer, diolah (2018)

Berdasarkan tabel 1 di atas, dapat dilihat hasil produksi jamur merang dengan menggunakan media tanam jerami berfluktuatif, hal ini dikarenakan beberapa faktor seperti suhu, kelembaban, dan perawatan selama proses tumbuh dan berkembang jamur merang. Suhu di dalam kumbung atau rumah jamur harus sangat dijaga, yaitu sekitar $30^{\circ} \mathrm{C}-35^{\circ} \mathrm{C}$. Apabila suhu tidak mencapai atau melebihi dari yang seharusnya, maka akan berakibat fatal bagi pertumbuhan dan perkembangan miselium. Kelembaban media dan lantai kumbung juga harus terjaga, jangan sampai terlalu kering atau terlalu basah. Selain itu, proses perawatan jamur merang juga harus diperhatikan, terutama pada saat musim hujan maupun cuaca terlalu panas hal ini dikarenakan media tanam jerami lebih sulit untuk menjaga kadar airnya, sehingga cepat kering dan perlu dilakukan penyiraman yang lebih.

Jamur merang dengan menggunakan media tanam jerami tidak berproduksi pada hari ke-empat, ke-lima, ke-sepuluh dan ke-sebelas, hal ini dikarenakan pada hari-hari tersebut jamur merang dalam masa istirahat, sehingga tidak mampu berproduksi. Perawatan harus sangat diperhatikan pada masa istirahat jamur merang, karena apabila perawatan dilakukan dengan

Studi Komparatif Budidaya Jamur Merang pada Media Jerami dan Media Tandan Kosong Kelapa Sawit 70 (Studi Kasus pada Usahatani Beuna Raseuki) di Gampong Peujeurat Desa Batoh Kecamatan Lueng Bata Banda Aceh (Syarifah Ulfami, Azhar, Edy Marsudi) 
baik, maka jamur merang akan mampu menghasilkan produksi dengan jumlah yang tinggi di hari berikutnya.

Tabel 2. Hasil Produksi Jamur Merang Media Tandan Kosong Kelapa Sawit

\begin{tabular}{ccccccccccccccc}
\hline $\begin{array}{c}\text { Periode } \\
\text { Tanam } \\
\text { (Produk } \\
\text { si Ke-) }\end{array}$ & \multicolumn{10}{c}{ TANDAN KOSONG KELAPA SAWIT (TKKS) } \\
\cline { 2 - 16 } & $\mathbf{1}$ & $\mathbf{2}$ & $\mathbf{3}$ & $\mathbf{4}$ & $\mathbf{5}$ & $\mathbf{6}$ & $\mathbf{7}$ & $\mathbf{8}$ & $\mathbf{9}$ & $\mathbf{1 0}$ & $\mathbf{1 1}$ & $\mathbf{1 2}$ & $\mathbf{1 3}$ & $\mathbf{1 4}$ \\
\hline $\mathbf{1}$ & 10 & 19 & 19 & 14 & 17,5 & 28,5 & 27,5 & 15,5 & 2 & 2 & 2,5 & 6 & 15,5 & 6 \\
$\mathbf{2}$ & 24,5 & 20,5 & 23,5 & 11 & 9 & 16,5 & 27 & 16 & 13 & 11 & 8 & 7 & 6,5 & 5 \\
$\mathbf{3}$ & 15 & 22 & 31,5 & 22 & 7 & 5 & 1 & 1,5 & 7,9 & 20,2 & 10,7 & 8 & 5 & 4 \\
$\mathbf{4}$ & 10 & 22 & 16,5 & 26,5 & 13 & 10 & 1,7 & 1 & 3 & 6,5 & 18 & 14 & 10 & 5 \\
$\mathbf{5}$ & 12,5 & 9 & 25,5 & 13 & 5,5 & 3 & 5 & 10 & 13 & 17,5 & 14,5 & 16 & 7,1 & 5,4 \\
$\mathbf{6}$ & 12 & 20 & 10 & 18 & 15 & 11 & 4 & 6,5 & 15 & 15,5 & 13,5 & 5 & 3,5 & 3,5 \\
\hline
\end{tabular}

Sumber: Data Primer, diolah (2018)

Berdasarkan tabel 2 dapat dilihat hasil produksi jamur merang dengan menggunakan media tanam tandan kosong kelapa sawit sangat berfluktuatif. Hal ini juga dikarenakan faktorfaktor seperti suhu, kelembaban dan perawatan. Jamur merang dengan menggunakan media tanam tandan kosong kelapa sawit lebih mampu menjaga kelembabannya dibandingkan dengan jamur merang yang menggunakan media tanam jerami. Perawatan jamur merang dengan menggunakan media tanam tandan kosong kelapa sawit lebih mudah. Penyiraman juga dilakukan tidak terlalu sering.

Jika ditotalkan hasil produksi jamur merang dengan menggunakan media tanam jerami pada periode ke-satu sampai ke-enam menghasilkan produksi masing-masing sebesar 117,5 kilogram, 121,9 kilogram, 107,4 kilogram, 87,4 kilogram, 95 kilogram, dan 88,7 kilogram. Sedangkan produksi total jamur merang dengan menggunakan media tanam tandan kosong kelapa sawit (TKKS) dari periode ke-satu sampai dengan ke-enam menghasilkan masingmasing produksi sebesar 185 kilogram, 198,5 kilogram, 160,8 kilogram, 157,2 kilogram, 157 kilogram, 152,5 kilogram. Maka, dapat dilihat besar selisih hasil produksi total antara jamur merang yang menggunakan media tanam jerami dengan jamur merang yang menggunakan media tanam tandan kosong kelapa sawit (TKKS) dari periode ke-satu sampai ke-enam yaitu masing-masing sebesar 67,5 kilogram, 76,6 kilogram, 53,4 kilogram, 69,8 kilogram, 62 kilogram, 63,8 kilogram.

\subsection{Analisis Biaya}

Tabel 3. Biaya Tetap yang dikeluarkan dalam Budidaya Jamur Merang

\begin{tabular}{lccccccc}
\hline No. & Uraian & Jumlah & Satuan & $\begin{array}{c}\text { Harga } \\
(\mathbf{R p})\end{array}$ & $\begin{array}{c}\text { Total } \\
\text { Biaya } \\
(\mathbf{R p})\end{array}$ & $\begin{array}{c}\text { Nilai } \\
\text { Sisa } \\
(\mathbf{R p} / \text { Tahun })\end{array}$ & $\begin{array}{c}\text { Biaya } \\
\text { Penyusutan }\end{array}$ \\
\hline 1. & Thermometer & 1 & Unit & 100.000 & 100.000 & 100 & 8.325 \\
2. & $\begin{array}{c}\text { Gerobak } \\
\text { Sorong }\end{array}$ & 1 & Unit & 400.000 & 400.000 & 400 & 16.650 \\
3. & Sistem & 1 & Unit & 3.500 .000 & 3.500 .000 & 3.500 & 145.688 \\
& Broiler & & & & & & \\
4. & Pisau & 4 & Bilah & 10.000 & 40.000 & 40 & 3.330 \\
$\mathbf{5 .}$ & Selang & 20 & Meter & 15.000 & 300.000 & 300 & 12.488 \\
6. & Sprayer & 1 & Tangki & 1.200 .000 & 1.200 .000 & 1.200 & 49.950 \\
\hline
\end{tabular}

Studi Komparatif Budidaya Jamur Merang pada Media Jerami dan Media Tandan Kosong Kelapa Sawit 


\begin{tabular}{cccccccc}
\hline No. & Uraian & Jumlah & Satuan & $\begin{array}{c}\text { Harga } \\
(\mathbf{R p})\end{array}$ & $\begin{array}{c}\text { Total } \\
\text { Biaya } \\
(\mathbf{R p})\end{array}$ & $\begin{array}{c}\text { Nilai } \\
\text { Sisa } \\
(\mathbf{R p} / \text { Tahun })\end{array}$ & $\begin{array}{c}\text { Biaya } \\
\text { Penyusutan }\end{array}$ \\
\hline 7. & Timba & 3 & Buah & 20.000 & 60.000 & 60 & 4.995 \\
8. & Timbangan & 1 & Unit & 200.000 & 200.000 & 200 & 8.325 \\
9. & Garu & 1 & Unit & 40.000 & 40.000 & 40 & 1.665 \\
$\mathbf{1 0 .}$ & Sanyo & 1 & Unit & 550.000 & 550.000 & 550 & 11.447 \\
11. & Bak & 1 & Unit & 2.000 .000 & 2.000 .000 & 2.000 & 41.625 \\
& Pencucian & & & & & & 46.620 \\
12. & Terpal & 2 & Lembar & 280.000 & 560.000 & 560 & 7.493 \\
13. & Ember Besar & 2 & Buah & 45.000 & 90.000 & 90 & $\mathbf{3 5 8 . 5 9 9}$ \\
\hline \multicolumn{7}{c}{ Total Biaya } \\
\hline
\end{tabular}

Sumber: Data Primer, diolah (2018)

Berdasarkan tabel 3 diatas, dapat dilihat bahwa biaya tetap yang dikeluarkan selama proses produksi jamur merang sebesar Rp 9.040.000 dan biaya penyusutan (biaya tetap yang dikeluarkan per periode) sebesar Rp. 358.599.

Tabel 3. Biaya Tidak Tetap (Variabel) yang dikeluarkan dalam Budidaya Jamur Merang selama Enam Kali Periode Tanam

\begin{tabular}{|c|c|c|c|c|c|c|c|}
\hline \multirow[b]{2}{*}{ No. } & \multirow[b]{2}{*}{ Uraian } & \multirow[b]{2}{*}{ Jumlah } & \multirow[b]{2}{*}{ Satuan } & \multicolumn{2}{|c|}{ Jerami } & \multicolumn{2}{|c|}{ TKKS } \\
\hline & & & & $\begin{array}{l}\text { Harga } \\
(\mathbf{R p})\end{array}$ & $\begin{array}{c}\text { Total } \\
\text { Biaya } \\
(\mathbf{R p}) \\
\end{array}$ & $\begin{array}{l}\text { Harga } \\
(\mathbf{R p})\end{array}$ & $\begin{array}{c}\text { Total } \\
\text { Biaya } \\
\text { (Rp) }\end{array}$ \\
\hline 1. & Bibit & 210 & Baglog & 8.000 & 1.680 .000 & 8.000 & 1.680 .000 \\
\hline 2. & $\begin{array}{l}\text { Jerami } \\
\text { Tandan }\end{array}$ & 3.600 & $\mathrm{Kg}$ & 600.000 & 3.600 .000 & & \\
\hline 3. & $\begin{array}{c}\text { Kosong } \\
\text { Kelapa sawit }\end{array}$ & 1.600 & $\mathrm{Kg}$ & & & 2.000 .000 & 4.000 .000 \\
\hline 4. & Dedak & 360 & $\mathrm{Kg}$ & 25.000 & 150.000 & 25.000 & 150.000 \\
\hline 5. & Sagu & 360 & $\mathrm{Kg}$ & 20.000 & 120.000 & 20.000 & 120.000 \\
\hline 6. & Kapur & 360 & $\mathrm{Kg}$ & 50.000 & 300.000 & 50.000 & 300.000 \\
\hline 7. & Kemasan & 6 & Ikat & 66.000 & 396.000 & 66.000 & 396.000 \\
\hline 8. & Listrik & & & 50.000 & 300.000 & 50.000 & 300.000 \\
\hline 9. & Kayu Bakar & 6 & Truk & 1.000 .000 & 6.000 .000 & 1.000 .000 & 6.000 .000 \\
\hline 10. & $\begin{array}{c}\text { Tenaga Kerja } \\
\text { Tetap }\end{array}$ & 1 & HKP & 1.500 .000 & 9.000 .000 & 1.500 .000 & 9.000 .000 \\
\hline 11. & $\begin{array}{l}\text { Tenaga Kerja } \\
\text { Fermentasi }\end{array}$ & 3 & HKP & 100.000 & 1.800 .000 & 100.000 & 1.800 .000 \\
\hline 12. & $\begin{array}{l}\text { Tenaga Kerja } \\
\text { Entri Media }\end{array}$ & 3 & HKP & 100.000 & 1.800 .000 & 100.000 & 1.800 .000 \\
\hline 13. & $\begin{array}{c}\text { Tenaga Kerja } \\
\text { Steam }\end{array}$ & 2 & HKP & 100.000 & 1.200 .000 & 100.000 & 1.200 .000 \\
\hline
\end{tabular}

Sumber: Data Primer, diolah (2018)

Berdasarkan tabel 3 di atas, dapat dilihat terdapat perbedaan biaya variabel yang dikeluarkan untuk masing-masing media tanam. Total biaya variabel yang dikeluarkan dalam budidaya jamur merang dengan menggunakan media tanam jerami senilai Rp. 26.346.000.

Studi Komparatif Budidaya Jamur Merang pada Media Jerami dan Media Tandan Kosong Kelapa Sawit 72 (Studi Kasus pada Usahatani Beuna Raseuki) di Gampong Peujeurat Desa Batoh Kecamatan Lueng Bata Banda Aceh (Syarifah Ulfami, Azhar, Edy Marsudi) 
Sedangkan biaya total variabel yang dikeluarkan dalam budidaya jamur merang dengan menggunakan media tanam tandan kosong kelapa sawit (TKKS) senilai Rp. 26.746.000. Dapat dilihat bahwa penggunaan media tanam tandan kosong kelapa sawit mengeluarkan biaya variabel yang lebih tinggi yaitu sebesar Rp. 400.000 dibandingkan dengan penggunaan media tanam jerami. Media jerami hanya dapat digunakan satu kali per periode tanam. Sedangkan media tandan kosong kelapa sawit dapat digunakan sebanyak tiga kali per periode tanam.

Pemakaian bibit per satu kali periode tanam sebanyak 35 baglog, sehingga dibutuhkan bibit sebanyak 210 baglog untuk enam kali periode tanam. Pemakaian media tanam jerami per satu kali periode tanam sebanyak 600 kilogram, sehingga dibutuhkan sebanyak 3.600 kilogram untuk enam kali periode tanam. Pemakaian tandan kosong kelapa sawit per tiga kali periode tanam yaitu sebanyak 800 kilogram, sehingga dibutuhkan media tanam tandan kosong kelapa sawit sebanyak 1.600 kilogram untuk enam kali periode tanam. Pemakaian dedak, sagu dan kapur per satu kali periode tanam masing-masing sebanyak 60 kilogram, sehingga dibutuhkan sebanyak 360 kilogram untuk enam kali periode tanam. Pemakaian dedak, sagu dan kapur per sekali tanam dibutuhkan sebanyak 60 kilogram dengan harga per 60 kilogram masing-masing sebesar Rp. 25.000., Rp. 20.000., dan Rp. 50.000., sehingga masing-masing konsentrat tersebut dibutuhkan sebanyak 360 kilogram untuk enam kali periode tanam.

Tenaga kerja tetap yang dibutuhkan hanya satu orang, dengan upah sebesar Rp. 1.500.000., per bulan atau per periode tanam. Sehingga upah yang dikeluarkan untuk tenaga kerja tetap selama enam bulan atau selama enam kali periode tanam sebesar Rp. 9.000.000. Tenaga kerja fermentasi dan entri media yang dibutuhkan sebanyak tiga orang dan tenaga kerja steam yang dibutuhkan sebanyak dua orang dengan masing-masing upah sebesar Rp. 100.000., per hari. Sehingga untuk enam kali waktu kerja, masing-masing upah yang dikeluarkan sebesar Rp. 1.800.000., Rp. 1.800.000., dan Rp. 1.200.000. Untuk tabel biaya tidak tetap (variabel) yang dikeluarkan dalam budidaya jamur merang dengan menggunakan media tanam jerami dan media tanam tandan kosong kelapa sawit per periode tanam.

Tabel 4. Hasil Perhitungan Analisis Pendapatan selama Enam Kali Periode Tanam

\begin{tabular}{cccccccc}
\hline \multirow{2}{*}{$\begin{array}{c}\text { Perhitu } \\
\text { ngan }\end{array}$} & \multirow{2}{*}{ Media } & \multicolumn{6}{c}{ PERIODE } \\
\cline { 3 - 7 } & & $\mathbf{1}$ & $\mathbf{2}$ & $\mathbf{3}$ & $\mathbf{4}$ & $\mathbf{5}$ & $\mathbf{6}$ \\
\hline \multirow{2}{*}{ TC } & Jerami & 4.749 .599 & 4.749 .599 & 4.749 .599 & 4.749 .599 & 4.749 .599 & 4.749 .599 \\
& TTKS & 6.149 .599 & 4.149 .599 & 4.149 .599 & 6.149 .599 & 4.149 .599 & 4.149 .599 \\
TR & Jerami & 5.875 .000 & 6.095 .000 & 5.370 .000 & 4.370 .000 & 4.750 .000 & 4.435 .000 \\
& TTKS & 9.250 .000 & 9.925 .000 & 8.040 .000 & 7.860 .000 & 7.850 .000 & 7.625 .000 \\
$\boldsymbol{\Pi}$ & Jerami & 1.125 .401 & 1.345 .401 & 620.401 & -379.599 & 401 & -314.599 \\
& TTKS & 3.100 .401 & 5.775 .401 & 3.890 .401 & 1.710 .401 & 3.700 .401 & 3.475 .401 \\
R/C & Jerami & 1,24 & 1,28 & 1,13 & 0,92 & 1 & 0,93 \\
& TTKS & 1,50 & 2,39 & 1,94 & 1,28 & 1,89 & 1,84 \\
\hline
\end{tabular}

Sumber: Data Primer, Diolah (2018)

Perhitungan total cost (TC) merupakan perhitungan untuk melihat besarnya total biaya yang dikeluarkan oleh usahatani jamur merang per periodenya. Total biaya yang dihitung meliputi total biaya budidaya jamur merang dengan menggunakan media tanam jerami dan total biaya budidaya jamur merang dengan menggunakan media tanam tandan kosong kelapa sawit (TKKS). Adapun cara untuk menghitung besarnya total cost yang dikeluarkan yaitu menjumlahkan biaya tetap dengan biaya variabel yang dikeluarkan. Total biaya yang dikeluarkan dari penggunaan media tanam jerami untuk setiap periodenya besarnya sama yaitu senilai Rp. 4.749.599., sedangkan total biaya yang dikeluarkan dari penggunaan media tanam tandan kosong kelapa sawit (TKKS) untuk beberapa periode berbeda. Total biaya yang

Studi Komparatif Budidaya Jamur Merang pada Media Jerami dan Media Tandan Kosong Kelapa Sawit 73 (Studi Kasus pada Usahatani Beuna Raseuki) di Gampong Peujeurat Desa Batoh Kecamatan Lueng Bata Banda Aceh (Syarifah Ulfami, Azhar, Edy Marsudi) 
dikeluarkan pada periode ke-satu dan periode ke-empat sebesar Rp. 6.149.559., sedangkan untuk periode ke-dua, periode ke-tiga, periode ke-lima dan periode ke-enam sebesar Rp. 4.149.599. Perbedaan total biaya yang dikeluarkan disebabkan oleh pengeluaran biaya variabel yang lebih sedikit untuk periode - periode tersebut. Pada periode ke-satu dan periode ke-empat, terdapat pengeluaran untuk media tanam. Sedangkan pada periode ke-dua, periode ke-tiga, periode ke-lima dan periode ke-enam tidak lagi memerlukan lagi pengeluaran berupa media tanam,karena masih menggunakan media tanam sebelumnya.

Perhitungan total revenue (TR) merupakan perhitungan untuk melihat besarnya total pendapatan yang akan diperoleh dengan memproduksi jamur merang per periodenya. Total pendapatan yang dihitung meliputi dari kedua produksi jamur merang baik menggunakan media tanam jerami maupun yang menggunakan media tanam tandan kosong kelapa sawit (TKKS). Adapun cara untuk menghitung total pendapatan (Total Revenue) yaitu mengalikan harga dengan kuantitas jamur merang (total jumlah jamur merang yang diproduksi). Total pendapatan yang diterima dari masing-masing penggunaan media tanam besarnya berbeda-beda, sesuai dengan total jumlah jamur merang yang diproduksi. Dapat dilihat dari tabel 6 diatas, total pendapatan produksi jamur merang dengan menggunakan media tanam tandan kosong kelapa sawit (TKKS) lebih tinggi dibandingkan dengan total pendapatan produksi jamur merang dengan menggunakan media tanam jerami. Hal ini menunjukkan kuantitas jamur merang dengan menggunakan media tanam tandan kosong kelapa sawit (TKKS) lebih tinggi dibandingkan dengan kuantitas jamur merang dengan menggunakan media tanam jerami.

Perhitungan pendapatan $(\pi)$ bertujuan untuk melihat keuntungan bersih yang diterima pada budidaya jamur merang. Adapun cara untuk menghitung pendapatan $(\pi)$ yaitu mengurangi total pendapatan (Total Revenue) dengan total biaya (Total Cost) yang dikeluarkan, meliputi biaya tetap dan biaya variabel. Dapat dilihat dari tabel 6 diatas, pendapatan budidaya jamur merang pada periode ke-empat dan periode ke-enam dengan menggunakan media tanam jerami tidak menutupi total biaya yang dikeluarkan, sehingga menghasilkan pendapatan minus (-).

Revenue cost/ratio (R/C Ratio) merupakan efisiensi usaha, yaitu ukuran perbandingan antara penerimaan usaha (Total Revenue/TR) dengan Total Biaya (Total Cost/TC). Dengan nilai $\mathrm{R} / \mathrm{C}$, maka dapat diketahui apakah suatu usaha tersebut menguntungkan atau tidak menguntungkan. Suatu usaha dapat dikatakan menguntungkan apabila nilai R/C dari usaha tersebut $>1$. Dari perhitungan Revenue cost/ratio (R/C Ratio) diatas, dapat dilihat bahwa nilai $\mathrm{R} / \mathrm{C}$ pada budidaya jamur merang dengan menggunakan media tanam jerami pada periode ke empat, ke lima dan ke enam $<1$, maka penggunaan media tanam jerami tidak dianjurkan karena tidak selalu memberikan keuntungan bagi budidaya jamur merang. Penggunaan media tanam tandan kosong kelapa sawit (TKKS) untuk budidaya jamur merang sangat dianjurkan karena nilai $\mathrm{R} / \mathrm{C}$ pada setiap periodenya $>1$.

\section{SIMPULAN DAN SARAN}

\section{Simpulan}

Berdasarkan hasil penelitian dan pembahasan, dapat diambil kesimpulan sebagai berikut, dari perhitungan Revenue cost/ratio (R/C Ratio) dapat dilihat bahwa nilai R/C pada budidaya jamur merang dengan menggunakan media tanam jerami pada periode ke empat, ke lima dan ke enam $<1$, maka penggunaan media tanam jerami tidak dianjurkan karena tidak selalu memberikan keuntungan bagi budidaya jamur merang. Penggunaan media tanam tandan kosong kelapa sawit (TKKS) untuk budidaya jamur merang sangat dianjurkan karena nilai R/C pada setiap periodenya $>1$. Adapun hasil uji statistik yang diperoleh yaitu 6,72641 >2,2281, maka $t_{\text {cari }}>t_{\text {tabel }}$ pada taraf nyata 0,05 . Hal ini menunjukkan bahwa terdapat perbedaan yang 
nyata antara pendapatan budidaya jamur merang yang menggunakan media tandan kosong kelapa sawit (TKKS) dengan pendapatan budidaya jamur merang yang menggunakan media jerami. Sehingga penggunaan media tanam tandan kosong kelapa sawit lebih menguntungkan dibandingkan dengan penggunaan media tanam jerami.

\section{Saran}

Adapun saran yang dapat penulis berikan sehubungan kesimpulan di atas adalah diharapakan kepada para petani yang masih menggunakan media tanam jerami dapat beralih menggunakan media tanam tandan kosong kelapa sawit, agar menghasilkan produksi jamur merang secara optimal sehingga mampu meningkatkan pendapatan dan keuntungan pada budidaya jamur merang.

\section{DAFTAR PUSTAKA}

Amalia, R. 2015. Analisis Faktor -Faktor Produksi dan Pendapatan Usahatani Kacang Tanah (Arachis hypogeae L) di Kecamatan Lembah Seulawah Kabupaten Aceh Besar. Skripsi. Jurusan Sosial Ekonomi Pertanian Fakultas Pertanian Universitas Syiah Kuala, Banda Aceh.

Anggit, P. 2010. Pemanfaatan Jerami Padi Dan Ampas Tahu Cair sebagai Media Pertumbuhan Jamur Merang (Volvariella volvaceae). Skripsi. Fakultas Keguruan Dan Ilmu Pendidikan Universitas Muhammadiyah, Surakarta.

A.T. Mosher. 1987. Menggerakkan dan Membangun Pertanian. Yasaguna, Jakarta.

Baridwan, Z. 2008. Sistem Akuntansi Penyusunan Prosedur dan Metode. Edisi Kelima. BPPE, Yogyakarta.

Cahyana Y. A., Muchrodji dan M. Bakrum. 1997. Jamur Tiram. Penebar Swadaya, Jakarta.

Cahyono. 2007. Kacang Buncis, Teknik Budidaya dan Analisis Usaha Tani. Penerbit Kanisius. Hal: 9-125.

Darmawi dan Suwadji. 1998. Pengaruh Iradiasi Dan Inkubasi Media Tandan Kosong Kelapa Sawit Terhadap Pertumbuhan Jamur Merang (Volvariella volvaceae). Apisora, BATAN.

Djelantik, A. A. MS. 1993. Pengaruh Lamanya Pengomposan Media Terhadap Produksi Jamur Merang. Majaiah Ilmiah 35 (I) : 132-140. Universitas Udayana, Denpasar.

Fitriani, R. 2017. Analisis Kelayakan Usaha Pemanfaatan Tandan Kosong Sawit untuk Budidaya Jamur Merang. Skripsi. Fakultas Ekonomi dan Manajemen. IPB, Bogor

Genders, R. 1986. Pedoman Berwiraswasta Bercocok Tanam Jamur. Dalam Mayun, I. A. (penulis). Pertumbuhan Jamur Merang (Volvariella volvaceae) pada Berbagai Media Tumbuh. Penerbit Unud, Denpasar. 
Hadi, E. W. 2003. Analisis Biaya dan Pendapatan Usahatani Jamur Merang (Studi Kasus Usahatani Jamur Merang pada Bapak Kasiadi dan Bapak Swantoro di Desa Gelang kecamatan Tulangan kabupaten Sidoarjo). http://studentresearch.umm.ac.id/index.php/dept_of_agribisnis/article/view/3078/0. Diakses tanggal: 11 April 2017.

Hanum, Chairani. 2008. Teknik Budidaya Tanaman. Jilid 1. Departemen Pendidikan Nasional. Buku Sekolah Elektronik, Jakarta.

Hastuti. 2007. Prinsip Dasar Ekonomi Pertanian. PT. Raja Grafindo, Jakarta.

Jumbriah. 2006. Bioremediasi Tanah Tercemar Diazinon Secara Ex Situ dengan Menggunakan Kompos Limbah Media Jamur (Spent Mushroom Compost). Tesis. Sekolah Pascasarjana. Institut Pertanian Bogor, Bogor.

Karimi, K. 2006. Conversion Of Rice Straw To Sugars By Dilute-Acid Hydrolysis. Journal of Biomass and Bioenergy, 30, 247-253.

Karsid, Aziz, R., dan Apriyanto, H. 2015. Aplikasi Kontrol Otomatis Suhu dan Kelembaban Untuk Peningkatan Produktivitas Budidaya Jamur Merang. Jurnal Aplikasi Teknologi Pangan, Vol.4 No. 3.

Lebu, B. 2013. Pembuatan Bioetanol dari Jerami Padi dengan Proses Fermentasi dengan Kapasitas Produksi 1000 Ton/ Tahun. Skripsi. Universitas Sumatera Utara, Medan.

Mayun, I. A. 2007. Pertumbuhan Jamur pada Berbagai Media Tumbuh. Skripsi. Fakultas Pertanian Universitas Udayana, Denpasar.

Meikalyan, R. 2016. Studi Komparasi Standar Pelayanan Minimal (Spm) Bus Trans Jogja. Skripsi. Program Studi Magister Teknik Sipil Program Pascasarjana Universitas Atma Jaya, Yogyakarta.

Nafi, A., Windrati, W. S., Diniyah, N., dan Shinta, M. P. 2014. Substitusi Jamur Merang (Volvariella volvaceae) dan Tepung Karo Pedang Termodifikasi (Canavalia ensiformis L.) pada Pembuatan Bakso Sapi. Jurnal Agroteknologi. 8(1).

Nazir, Moh. 2005. Metode Penelitian. Ghalia Indonesia, Jakarta.

Nicholson, W. 1999. Mikro Ekonomi, Prinsip Dasar dan Perluasan. Jilid 2. Edisi Kelima. Binarupa Aksara, Jakarta.

Ningtyas, V.A dan L.Y. Astuti. 2009. Pemanfaatan Tandan Kosong Kelapa Sawit Sisa Media Jamur Merang (Volvariella volvacea) sebagai Pupuk Organik dengan Penambahan Aktivator Effective Microorganism EM-4. http://www.deptan.go.id. Diakses tanggal: 11 April 2017.

Nur Ichsan, C., Harun, F., dan Ariska, N. 2011. Karakteristik Pertumbuhan dan Hasil Jamur Merang (Volvariella volvacea L.) Pada Media Tanam Dan Konsentrasi Pupuk Biogreen yang Berbeda. Jurnal Floratek. 171-180. 
Oktaviana, T. 2013. Analisis Pendapatan Usahatani dan Tataniaga Jamur Merang (Volvariella volvaceae) di Desa Gempol Kolot, Kecamatan Banyusari, Kabupaten Karawang. Skripsi. IPB, Bogor.

PPKS. 2005. Budidaya Kelapa Sawit. Pusat Penelitian Kelapa Sawit Medan. Sumatara Utara.

Rahim. 2008. Pengantar Teori dan Kasus Ekonomika Pertanian. Penebar Swadaya, Jakarta.

Saputri, A. 2011. Analisis Pengaruh Kualitas Pelayanan dan Kepuasan Konsumen Terhadap Loyalitas Pelanggan pada Swalayan Hardjono Baturetno. Skripsi. Universitas Muhammadiyah Surakarta, Surakarta.

Serambi Aceh. Berita: Permintaan jamur Merang meningkat. http://aceh.tribunnews.com/2016/01/14/permintaan-jamur-merang-meningkat. Diakses tanggal: 11 April 2017.

Sinaga, M. S. 2001. Jamur Merang dan Budidayanya. Penebar Swadaya, Jakarta.

M. S. 2005. Jamur Merang dan Budidayanya. Penebar Swadaya, Jakarta.

M. S. 2008. Jamur Merang dan Budidayanya. Penebar Swadaya, Jakarta.

M. S. 2009. Jamur Merang dan Budidayanya. Penebar Swadaya, Jakarta.

Sinus. 2014. Analisis Tingkat Pendapatan Usaha Budidaya Jamur Merang di Desa Kampuh Kecamatan Bonti. Skripsi.

Soeharjo dan Patong. 1973. Sendi-Sendi Pokok Usaha Tani. Departemen Ilmu Sosial Ekonomi. Fakultas Pertanian, Institut Pertanian Bogor, Bogor.

Soekartawi. 2005. Agribisnis Teori dan Aplikasinya. Raja Grafindo Persaja, Jakarta.

Sudjana. 2002. Metode Statistika. Tarsito, Bandung.

Sunandar, B. 2010. Budidaya Jamur Merang. BPTP, Bandung.

Suratiyah. 2006. Ilmu Usahatani. Swadaya, Jakarta.

Susilawati, E. 1998. Potensi dan Teknik Pengomposan Tandan Kosong Kelapa Sawit. Warta Pusat Penelitian Kelapa Sawit. Jurnal . 6(2), 77-82.

Wahidah, Fartahul, B., dan Saputra. 2015. Perbedaan Pengaruh Media Tanam Serbuk Gergaji dan Jerami Padi Terhadap Pertumbuhan Jamur Tiram Putih (Pleurotus ostreatus). Jurnal Ilmiah Biologi. 3(1), 11-15.

Widiastuti dan Panji, T. 2007. Pemanfaatan Tandan Kosong Kelapa Sawit Sisa Jamur Merang (Volvariella volvaceae) (TKSJ) sebagai Pupuk Orgnaik pada Pembibitan Kelapa Sawit. Jurnal Menara Perkebunan 75(2), 70-79. Balai Penelitian Bioteknologi Perkebunan Indonesia, Bogor.

Wirartha, I.M. 2006. Metodologi Penetilian Sosial Ekonomi. C.V Andi Offset, Yogyakarta. 
Zuyasna, Nasution, M., dan Fitriani, D. 2011. Pertumbuhan dan Hasil Jamur Merang Akibat Perbedaan Media Tanam dan Konsentrasi Pupuk Super A-1. Jurnal Forensik. 6, 92103. 